Article

\title{
Peak Shaving through Battery Storage for Low-Voltage Enterprises with Peak Demand Pricing
}

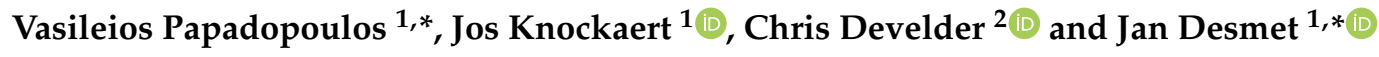 \\ 1 Lemcko, Department of Electromechanical, Systems and Metal Engineering, Ghent University, 8500 Kortrijk, \\ Belgium; Jos.Knockaert@UGent.be \\ 2 IDLab, Department of Information Technology, Ghent University_Imec, 9000 Gent, Belgium; \\ Chris.Develder@UGent.be \\ * Correspondence: Vasileios.Papadopoulos@UGent.be (V.P.); Janj.Desmet@UGent.be (J.D.)
}

Received: 30 January 2020; Accepted: 1 March 2020; Published: 5 March 2020

\begin{abstract}
The renewable energy transition has introduced new electricity tariff structures. With the increased penetration of photovoltaic and wind power systems, users are being charged more for their peak demand. Consequently, peak shaving has gained attention in recent years. In this paper, we investigated the potential of peak shaving through battery storage. The analyzed system comprises a battery, a load and the grid but no renewable energy sources. The study is based on 40 load profiles of low-voltage users, located in Belgium, for the period 1 January 2014, 00:00-31 December 2016, 23:45, at $15 \mathrm{~min}$ resolution, with peak demand pricing. For each user, we studied the peak load reduction achievable by batteries of varying energy capacities ( $\mathrm{kWh}$ ), ranging from 0.1 to 10 times the mean power $(\mathrm{kW})$. The results show that for $75 \%$ of the users, the peak reduction stays below $44 \%$ when the battery capacity is 10 times the mean power. Furthermore, for $75 \%$ of the users the battery remains idle for at least $80 \%$ of the time; consequently, the battery could possibly provide other services as well if the peak occurrence is sufficiently predictable. From an economic perspective, peak shaving looks interesting for capacity invoiced end users in Belgium, under the current battery capex and electricity prices (without Time-of-Use (ToU) dependency).
\end{abstract}

Keywords: peak shaving; battery storage; peak demand pricing; lithium-ion; tariff structure

\section{Introduction}

Over the past decade, most countries all over the world have taken action towards reducing their polluting emissions by investing in renewable energy sources. Among those sources, particularly, photovoltaic (PV) solar panels and wind power systems have seen a significant growth [1]. However, the increase of renewables goes hand in hand with technical challenges. The stochasticity of both PV and wind power systems causes the maintenance of grid stability to become more difficult $[2,3]$.

A major stakeholder impacted by the renewable energy transition is the distribution network operator. While end users are becoming increasingly more independent from the grid, the revenue constraint for the grid operator still remains [4]. Under the current tariff structure, which is primarily based on the energy-volume component, a 'death spiral' phenomenon is imminent [4,5]. Nevertheless, the grid infrastructure costs are mainly dependent on the power capacity of the system. Yet, PV users have reportedly slightly lower peak power than non-PV users [6]. In other words, PV-users pay less than non-PV users even though both of them use the grid almost to the same extent [6]. To counteract such unfairness between different user groups and correctly attribute the costs to their origin, new tariff structures are being introduced that increase the weight factor for the peak demand component. This (peak demand pricing) will also apply for small user groups such as residential consumers who have been so far excluded from peak power measurements $[7,8]$. 
Given these increased peak power costs, peak demand reduction ('peak shaving') has gained much attention in recent years. Peak shaving is not a new concept; industrial users with high peak demand already have been using diesel and gas generators to reduce electricity costs for a long time. Still, those conventional generation methods are expected to be replaced by 'green' technologies, among which energy storage and in particular batteries are the primary candidate.

Battery storage systems have been deployed in the past to provide different types of services, such as (i) increasing the self-sufficiency of PV/wind power installations [9-11], (ii) providing ancillary services to the grid operator [12-14], (iii) peak shaving [15-17], (iv) back-up generators and UPS [18,19]. A common issue, arising particularly in (i), (ii) and (iii), is that due to the high cost of the storage system, battery storage investments are not yet economically feasible. However, we note that in the majority of those studies, the battery is deployed exclusively for one service. Therefore, to accelerate the return of investment, many suggest as a possible solution 'hybridizing' multiple services into a single application instead of providing each one separately $[14,20,21]$. Before studying how such a hybrid strategy can be applied, we should first identify the technical constraints of the services under consideration. In this paper, we focus specifically on peak shaving and present some insights that reflect its potential for hybridization. In the next paragraph, we review previous research works on peak shaving through battery storage.

In [15], the authors present a sizing methodology for defining the optimal energy and power capacity of battery storage systems used for peak shaving. An economic feasibility study was conducted for two different technologies, lead acid and vanadium redox flow (VRF). A control strategy was proposed, but it assumed that the load profile is perfectly predictable in advance. In [16], the researchers applied peak shaving for residential end users. One of the main conclusions was that the utilization of the lithium-ion battery stays very low, lower than 165 cycles per year. At such a low rate (here, the cycle lifetime is 3000 cycles) the system could be used for more than 20 years unless it exceeded its calendar lifetime. Finally, considering also its calendar lifetime, the battery would have to be replaced approximately after 10-15 years. Furthermore, the researchers suggested adding grid support services next to peak shaving in order to increase the utilization of the system. In [22], the researchers developed a model in Matlab/Simulink where a VRF battery is used to simultaneously provide frequency regulation and peak shaving. It was concluded that the battery storage system can successfully perform both services. However, the experiment was conducted only for a limited time period (30-140 s), thus, in essence, without affecting the battery state of charge $(\mathrm{SoC})$ and as a consequence, it was not possible to evaluate the reliability of the control system under unfavorable conditions. In [23], a fuzzy control algorithm was developed for peak shaving in university buildings. The algorithm was tested and compared to two different peak shaving techniques, namely the fixed-threshold and adaptive-threshold controller. The results showed that the proposed algorithm was the best of all. Although the researchers conducted several case studies (with 8 different load profiles), they did not provide sufficient information about the load forecasting method. In [17], a control algorithm is proposed for peak shaving in low-voltage distribution networks based on day ahead aggregated load forecasts. The main novelty of that study is that the algorithm, considering also the inherent forecasting errors, relies solely on historic data; hence there is no need to intervene in real-time and readapt the dis-charging process of the battery. Results from a case study show that peak reduction is achieved for $97 \%$ of the time and that for $55 \%$ of the time, the peak reduction is at least $10 \%$. In $[18,19,24,25]$, peak shaving is addressed as a secondary application. Here, the primary service of the battery is to provide uninterruptible power supply (UPS) in data centers. The researchers argue that because of the significantly low probability of the peak occurrence (e.g., a Google data center exceeds $90 \%$ of its power capacity only for $1 \%$ of the time), it is possible to achieve peak reduction without impacting the reliability of the primary service. In [26], a battery sizing methodology and an optimal control algorithm is proposed for peak shaving in industrial and commercial customers. One of the main objectives was to determine an appropriate peak shaving threshold. Three case studies were carried out, each one considering a different daily load profile. The results showed that adapting the peak 
shaving threshold in real-time leads to higher peak reduction than keeping a fixed threshold based only on a historic data analysis. A drawback of the study might be that when calculating the battery utilization, it is assumed that the battery is equally utilized every weekday of the year, thus omitting possible idle periods on days with low power consumption. In [27], a peak shaving algorithm was proposed for microgrid applications. In contrast to conventional approaches considering only the load consumption, here, the peak threshold applies also for the PV generation. The battery capacity is equally reserved for both positive (injection to the grid) and negative (absorption from the grid) peaks by setting the SoC during normal operation at $50 \%$. The algorithm was tested on a real-time microgrid, implemented in the lab. The researchers used predefined data (load/PV profiles) to carry out the experiment; however, they did suggest in future deploying predictive analytics to improve the reliability of the system.

In this paragraph, we explain three major contribution pillars of the present research work.

i. Dataset: First, an important conclusion to note, resulting from our literature review is that all previous studies refer to unique use cases. Moreover, in almost all previous studies, the data was very limited (max 2-3 months); thus, the seasonal periodicity was not present. To the best of our knowledge, the present study is the first to consider such large dataset: 40 load profiles (in the Supplementary Materials), each one with 3 full years of historic load power. Knowing the difficulties of finding qualitative data, we decided to make this dataset publicly available (The dataset is available as attachment to this manuscript. Or contact Vasileios.Papadopoulos@ugent.be) in order to stimulate further research on this topic.

ii. Sizing methodology: Secondly, aside from the extended datasets, another thing that has been missing from the existing literature on peak shaving, which has focused mainly on control strategies, is a concrete methodology of sizing the battery capacity. In the present paper, we demonstrate how to calculate the minimum battery capacity requirement by combining a power flow model with the dichotomy optimization algorithm.

iii. Quantitative results: Thirdly, in our attempt to strengthen the validity of our conclusions, we provide an overview of quantitative results from all 40 different use cases. We show both energetic assessments and economic results. The third contribution pillar can be summarized in answering the following:

- How much peak demand reduction can a user achieve for a given battery energy capacity $(\mathrm{kWh})$ ?

- What is the battery utilization, how much time during the year and how many cycles? Does peak shaving heavily impact the degradation of the battery? Can we hybridize peak shaving with other services?

- Which performance metrics should we use and how can these be interpreted from an economic perspective? What are the profitability margins of battery storage for Belgium?

The rest of the paper is structured as follows. In Section 2, the data of the study are presented (Section 2.1). Then, we proceed with the methodology; the power flow model is explained (Section 2.2) and the dichotomy method is proposed as an optimization algorithm (Section 2.3). Section 2 closes with the definition of performance metrics (Section 2.4). Next, Section 3 shows the results of the simulation (Section 3.1) and explains how to interpret those from an economic perspective (Section 3.2). Finally, Section 4 summarizes the most important conclusions and makes suggestions for future research objectives. 


\section{Materials and Methods}

\subsection{Data}

We received 40 load profiles from the Flemish distribution grid operator (Fluvius) Each profile is the active power (in $\mathrm{kW}$ ) of an enterprise for the 3-year period between 1 January 2014, 00:00 and 31 December 2016, 23:45. All enterprises are low-voltage users with peak demand pricing and a connection capacity above $56 \mathrm{kVA}$ and lower than $1 \mathrm{MVA}$. The data was logged through automatic measurement reading (AMR) devices with a time resolution of $15 \mathrm{~min}$. The mean power of the users varied between 1.92 and $53.75 \mathrm{~kW}$ (Figure 1a). The peak-to-mean power ratio was between 1.5 and 40 ; however, for $90 \%$ of the users, the ratio is lower than 10 (Figure $1 \mathrm{~b}$ ).
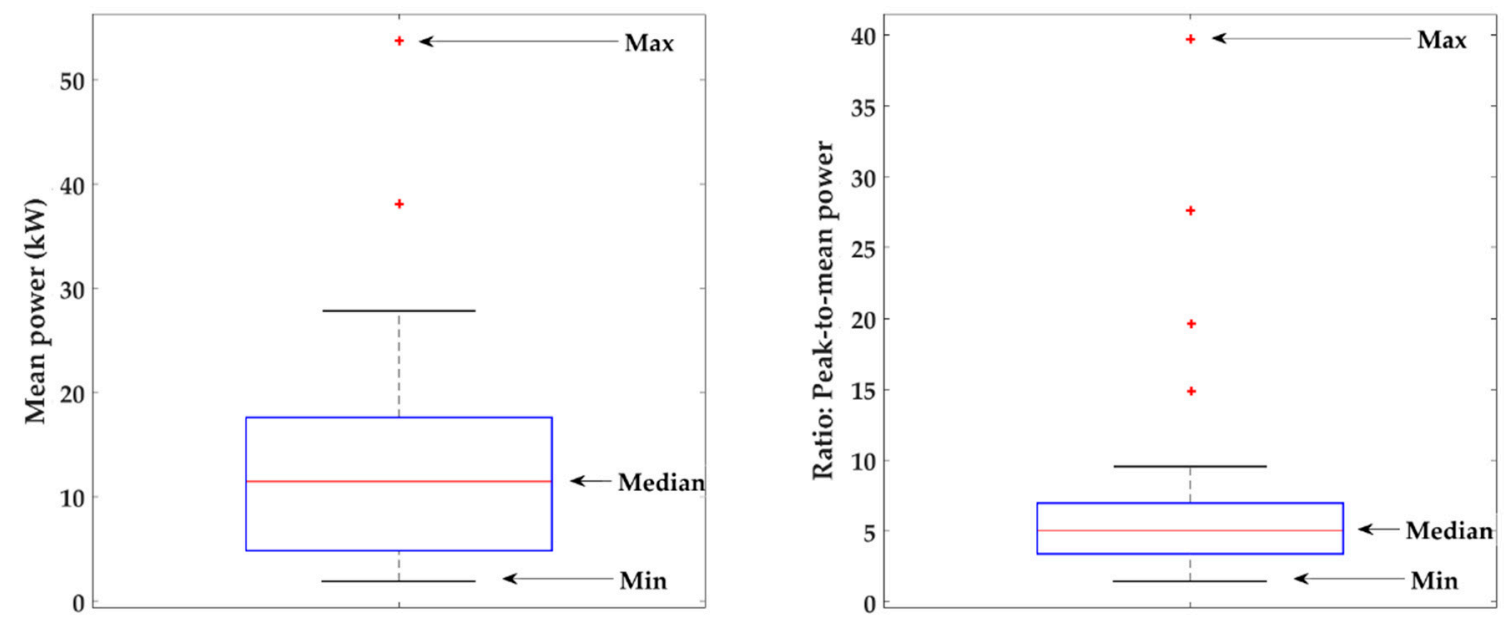

Figure 1. Boxplots, 40 load profiles-(a) Mean power (left), (b) Ratio: Peak-to-mean power (right).

\subsection{Power Flow Model}

Figure 2 shows the topology of our system. The battery is connected through a DC/AC inverter behind the meter of the user. The grid serves as the only power supply since there are no renewable energy sources. In general, for peak shaving, the energy storage system should have high energy efficiency as well as high power capacity (C rate) [28]. For these reasons, we selected a Lithium-ion battery to carry out our analysis (See Table 1).

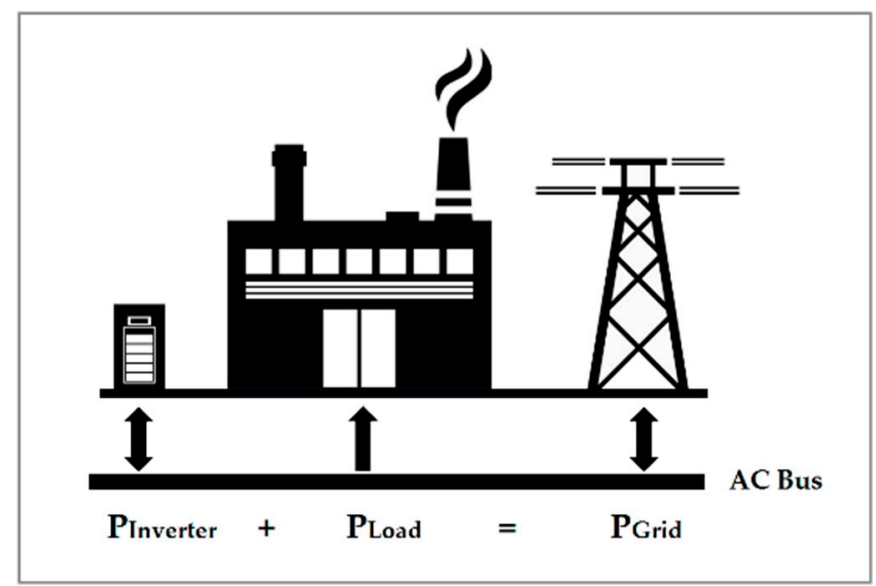

Figure 2. System topology. 
Table 1. LFP Cell Characteristics, according to [29].

\begin{tabular}{cc}
\hline Characteristics & Specifications \\
\hline Chemistry & $\mathrm{LiFePO}_{4}$ \\
Energy capacity & $2.28 \mathrm{Ah}(7.52 \mathrm{Wh})$ \\
Nominal voltage & $3.3 \mathrm{~V}$ \\
Operating voltage & 2.5 to $3.6 \mathrm{~V}$ \\
Operating temperature & $-30{ }^{\circ} \mathrm{C}$ to $+60^{\circ} \mathrm{C}$ \\
Cell weight & $70 \mathrm{~g}$ \\
\hline
\end{tabular}

The simulation model, built in Matlab/Simulink is shown in Figure 4. Here, it is worth noting that a part of the present model used for peak shaving was based on the model described in [30]. Therefore, in this paper, we will only detail the new model components, which are blocks 1 and 5 (See Figure 4). For the remaining blocks 2, 3 and 4, we provide a generic description, but for more information, the reader is referred to [30], in particular its Section 2.3. For the development of the model, we relied heavily on a real test-setup-microgrid emulator (The microgrid emulator makes part of the laboratory infrastructure of EELab/Lemcko, an expertise center of Ghent university, specialized in Renewable Energy System applications. For more information, contact the first author (Vasileios.Papadopoulos@UGent.be)) comprising of: (i) a low-voltage grid (250 kVA power source), (ii) a $90 \mathrm{kVA}$ DC/AC converter, (iii) a $20 \mathrm{kWh} \mathrm{LiFePO}_{4}$ battery, (iv) a 30-kW programmable load. The behavior of each component and the interaction between them was studied analytically and converted into simulation models using information from test measurements, scientific papers and commercial datasheets.

To begin with, the model has three variables: (i) the time resolution of the load profile, (ii) the battery capacity $(\mathrm{kWh})$ and (iii) its $\mathrm{C}$ rate. Furthermore, it receives two data inputs: (i) the load profile and (ii) a power threshold. The load profile is simply a time series of the active power in $\mathrm{kW}$ at $15 \mathrm{~min}$ resolution. The power threshold is a constant specifying the 'desired' maximum power. This value must be lower than the peak power but also higher than the mean power. Given the time step (resolution) and the 3-year period, in total, there are 105,216 simulation steps (1096 days $\times 96$ quarters/day). At each step, the model reads the load power of that moment and the current State-of-Charge (SoC). Then, it undergoes three sequential processes $(1,2$ and 3$)$ to calculate the battery power $P_{\text {bat }}$ (inverter's DC side), the inverter power $P_{\text {inv }}$ (inverter's AC side) and the power of the grid $\mathrm{P}_{\text {grid. }}$. Next, after updating the State-of-Charge $(\mathrm{SoC})$ of the battery, it proceeds to the next simulation step and hence, the simulation progresses. Figure 3 shows the DC/AC conversion efficiency of the inverter in charging mode. Additionally, all the equations that were used to calculate the inverter power $P_{\text {inv }}$ and battery power $P_{\text {bat }}$ in charging and discharging mode.

$$
\begin{gathered}
P_{\text {bat }}=f(x) \cdot P_{\text {inv }} \\
\frac{P_{\text {bat }}}{P_{\text {nom }}}=f(x) \cdot \frac{P_{\text {inv }}}{P_{\text {nom }}} \\
\frac{P_{\text {bat }}}{P_{\text {nom }}}=f(x) \cdot x=g(x) \\
\frac{P_{\text {inv }}}{P_{\text {nom }}}=g^{-1}\left(\frac{P_{\text {bat }}}{P_{\text {nom }}}\right) \\
\frac{P_{\text {bat }}}{f}=\frac{P_{\text {inv }}}{f(x)} \\
\frac{P_{\text {bat }}}{P_{\text {nom }}}=\frac{P_{\text {inv }}}{P_{\text {nom }}} \cdot \frac{1}{f(x)} \\
\frac{P_{\text {bat }}}{P_{\text {nom }}}=\frac{x}{f(x)}=h(x)
\end{gathered}
$$




$$
\frac{\mathrm{P}_{\text {inv }}}{\mathrm{P}_{\text {nom }}}=\mathrm{h}^{-1}\left(\frac{\mathrm{P}_{\text {bat }}}{\mathrm{P}_{\text {nom }}}\right)
$$

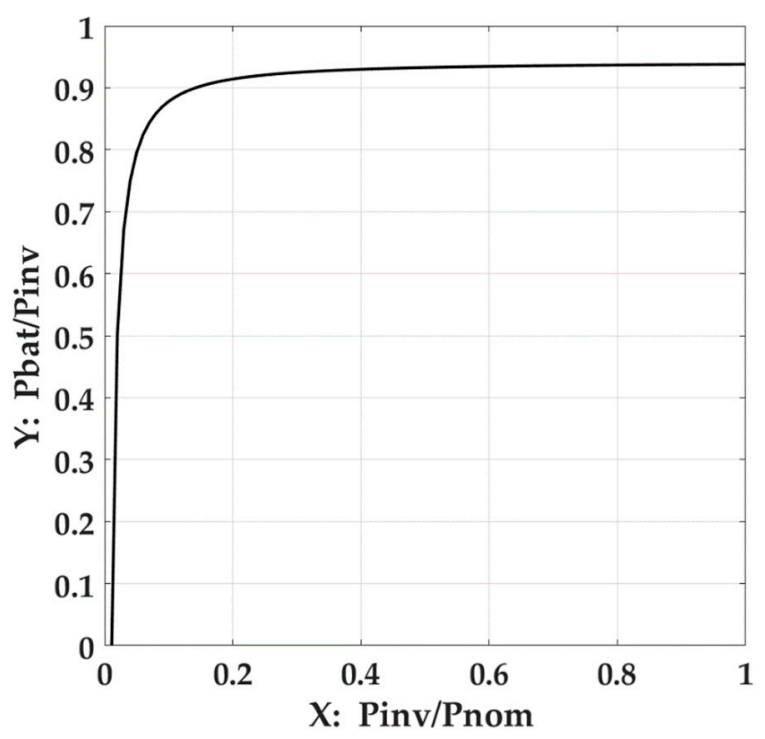

Figure 3. DC/AC efficiency, $\mathrm{Y}=\mathrm{f}(\mathrm{x})$.

With respect to the sequential processes, process 1 performs the power conversion from AC to DC compensating for the efficiency losses (AC to DC). Process 2 applies two saturation constraints to the battery power: one for the given $\mathrm{C}$ rate and one for the given time resolution. Finally, process 3 performs the reverse conversion from $\mathrm{DC}$ to $\mathrm{AC}$ considering the inverse (DC to $\mathrm{AC}$ ) efficiency losses. In the following paragraph, we describe with more detail those processes.

Process 1-AC/DC power conversion (Figure 4, block 1): Initially, we set the inverter power equal to the difference $\mathrm{P}_{\text {Threshold }}-\mathrm{P}_{\text {load }}$. In case of a power surplus (positive difference), the inverter is in charging mode to restore the battery's energy capacity, otherwise, in case of a power deficit (negative difference), the inverter is in discharging mode to shave the peak. After setting the inverter power, next, we calculated the battery power compensating for the efficiency losses. In charging mode, the battery power is always lower than the inverter power (See Equation (1)) and vice versa in discharging mode the battery power is always higher than the inverter power (See Equation (5)).

Process 2-Power saturation constraints (Figure 4, block 2,3, 4): Here, we impose two constraints to the battery power. First (block 2), the battery power can never exceed its power capacity as specified by its $C$ rate limit and the SoC level. For this battery technology, the recommended $C$ rate is 1 . How we calculate exactly the power from the $C$ rate limit, has been explained in [30], Section 2.3. (As an approximation, we can state that the power capacity is equal to the battery's nominal voltage times the $C$ rate, times its energy capacity in $A h: P_{\text {bat max }}=U_{\text {nom }} \cdot C_{\text {rate }} \cdot C_{A h}$.) Second (block 3), we must take into account also the time resolution of our data $(15 \mathrm{~min})$. This constraint comes into effect when the SoC level is very close either to its upper or lower limit ( $90 \%$ and $10 \%$ respectively) $(10-90 \%$ is the recommended by the manufacturer SoC range to maximize the lifetime of the battery). Since our simulation is executed in discrete steps of $15 \mathrm{~min}$, we need to consider how much energy is left inside the battery and saturate its power accordingly (see [30], Section 2.3). Afterwards, at the output of the second constraint, the battery power was finally defined and hence the SoC can be updated (block 4). 


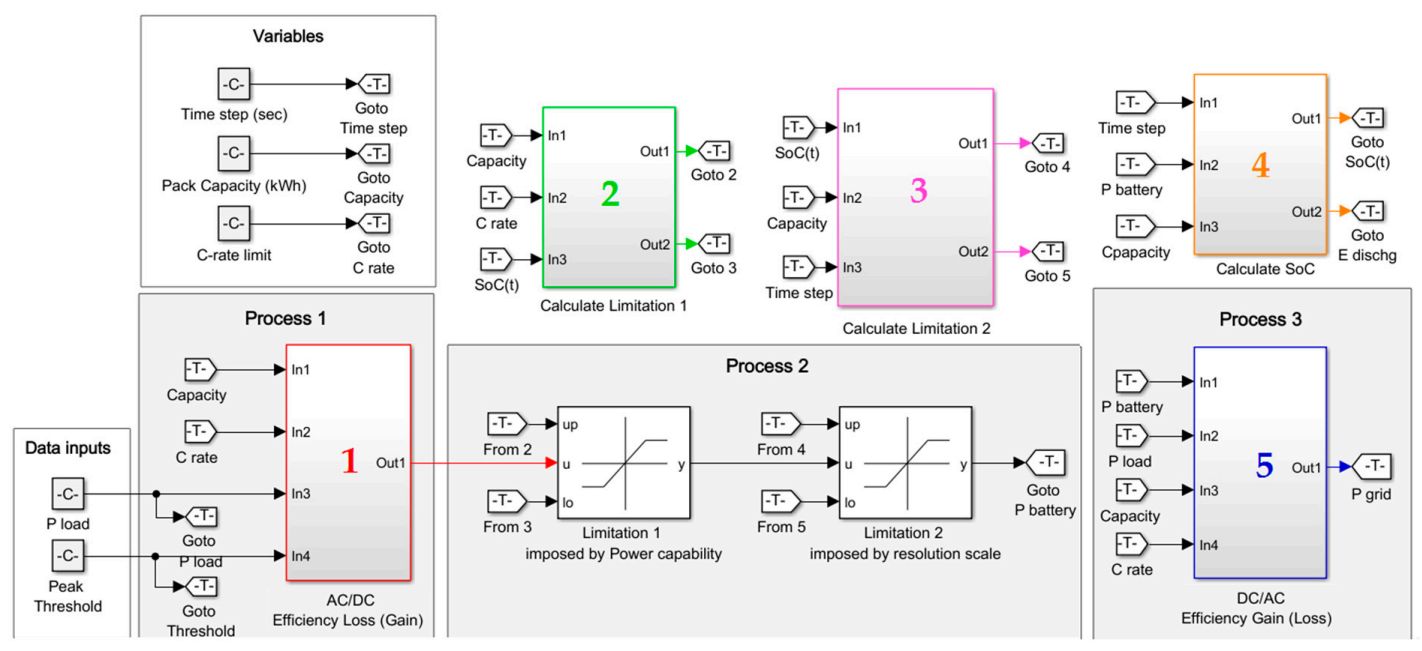

(a) Main model
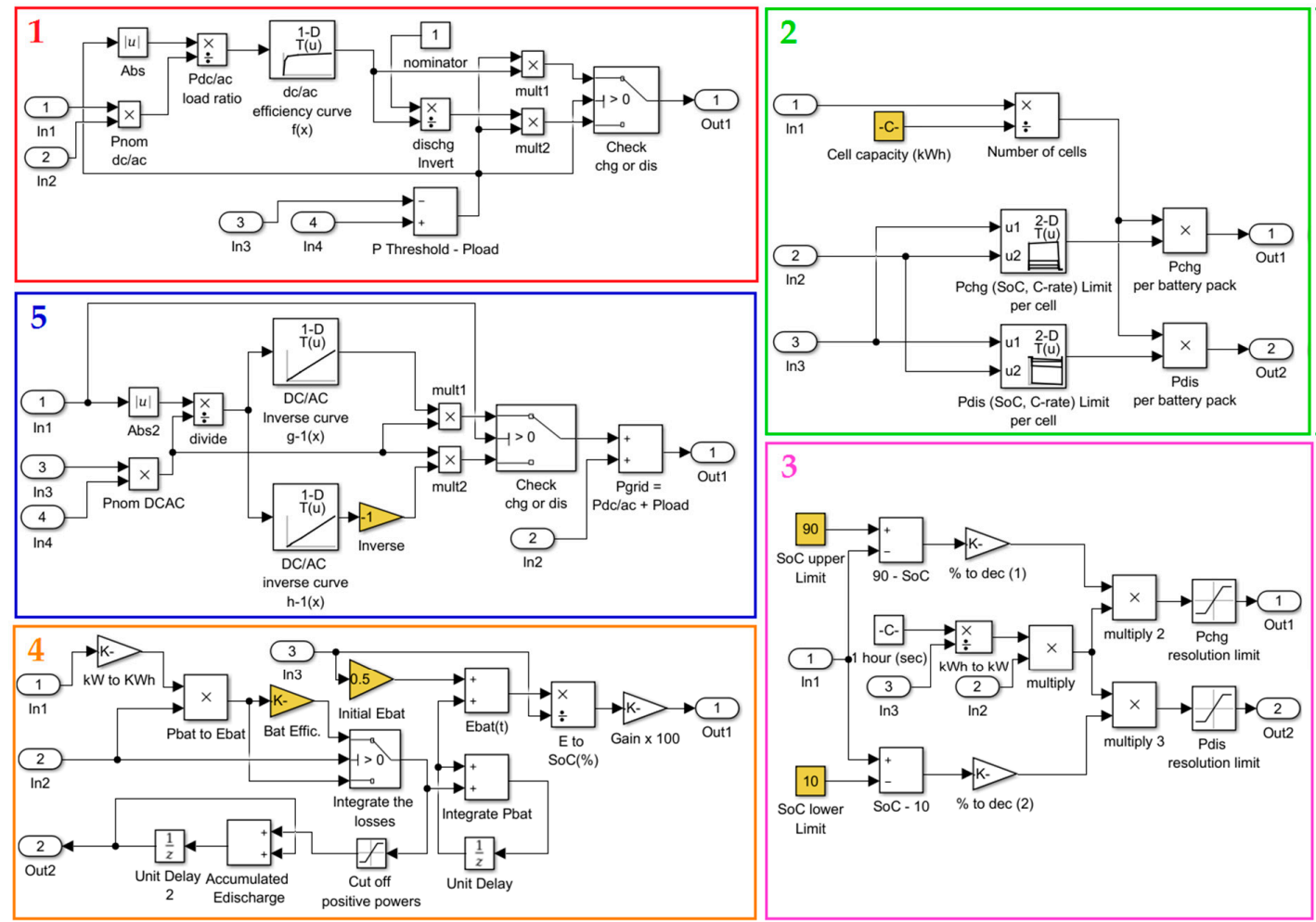

(b) Subsystem components

Figure 4. Power flow model for peak shaving designed in Matlab/Simulink.

Process 3-DC/AC power conversion (Figure 4, block 5): Knowing the final value of the battery power, it is then possible to calculate the final value of the inverter power. At this point, the DC/AC efficiency function $f(x)$ needs to be inverted. In charging mode, we make use of Equation (4) (function $\mathrm{g}^{-1}$ ) and in discharging mode Equation (8) (function $\mathrm{h}^{-1}$ ). As a result, we finally know both the load power $P_{\text {load }}$ and the inverter power $P_{\text {inv }}$. Therefore, we can also calculate the power of the grid $\mathrm{P}_{\text {grid }}$ $\left(\mathrm{P}_{\text {grid }}=\mathrm{P}_{\text {load }}+\mathrm{P}_{\text {inv }}\right)$ and proceed to the next simulation step. 


\subsection{Dichotomy Method}

As already mentioned in Section 2.2, the Simulink model receives both the battery capacity (as variable) and a peak threshold (as data input). To find out whether or not that threshold will be met, all we have to do is run the simulation and check the maximum load power $\operatorname{Max}\left(\mathrm{P}_{\text {load }}\right)$. On the one hand, if the threshold is too low, the system will be unreliable ( $\left.\operatorname{Max}\left(\mathrm{P}_{\text {load }}\right)>\mathrm{P}_{\text {Threshold }}\right)$ due to insufficient battery capacity, whereas, on the other hand, if the threshold is too high $\left(\operatorname{Max}\left(\mathrm{P}_{\text {load }}\right) \leq \mathrm{P}_{\text {Threshold }}\right)$ the system will be reliable but the battery is overdimensioned. Consequently, for each load profile and a given battery capacity, there is only one threshold that minimizes the load power (See Figure 5). To find the solution for our optimization problem we deployed the 'dichotomy method'. In the next paragraph, follows a short description of the algorithm.
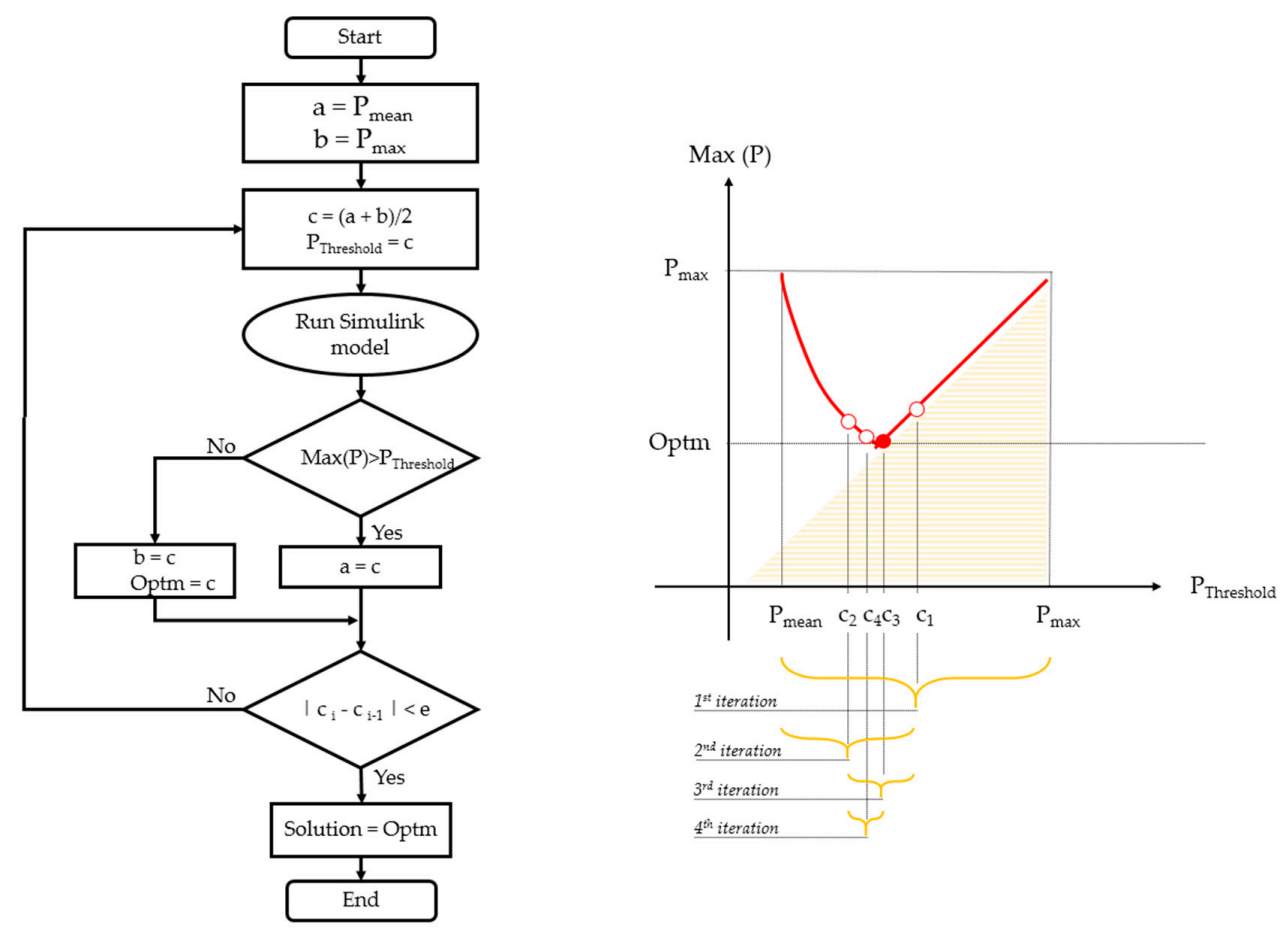

Figure 5. Flow chart-Dichotomy method: (a) Pseudocode (left), (b) Midpoint evolution (right).

Dichotomy method (Figure 5):

1. Initialize the lower and upper threshold limit at $\mathrm{a}=\mathrm{P}_{\text {mean }}$ and $\mathrm{b}=\mathrm{P}_{\max }$, respectively.

2. Enter dichotomy loop: Calculate the midpoint at $c=(a+b) / 2$ and set the peak threshold equal to that value.

3. Run the Simulink model.

4. Check the maximum load power. If the load power exceeds the threshold update the lower limit at $\mathrm{a}=\mathrm{c}$. Otherwise, update the upper limit $\mathrm{at} \mathrm{b}=\mathrm{c}$ and store that value as the current solution.

5. Check convergence criterion. If the distance between the current and previous midpoint is lower than a constant, exit the loop, otherwise, go to step 2 and recalculate the new midpoint.

\subsection{Definition of Performance Metrics}

Before continuing with the presentation of the simulation results, first, we need to give the definitions of our performance metrics, based on which we evaluated the peak shaving potential of the users. In our approach, we would rather associate the word 'potential' explicitly to energetic assessments. The extent to which these can be translated into economic terms (e.g., revenues, expenses, ROIs) depends certainly on the tariff structure under consideration as well as the cost for the battery 
storage system. Although, as shown in Section 3, we do provide some insights specifically for Belgium, preferably, each reader ought to make his own reflections.

Peak reduction (\%): It is the percentual difference between the initial peak power and the final peak power after peak shaving:

$$
\mathrm{A}_{\text {peak red }}=\frac{\mathrm{P}_{\max \mathrm{i}}-\mathrm{P}_{\max \mathrm{f}}}{\mathrm{P}_{\max \mathrm{i}}} \cdot 100
$$

where $A_{\text {peak red }}$ is the peak reduction, $\mathrm{P}_{\max }$ is the initial peak power, $\mathrm{P}_{\max \mathrm{f}}$ is the final peak power after peak shaving.

Peak reduction-to-capacity: It is the difference between the initial peak power and the final peak power after peak shaving divided by the battery capacity. This metric can serve us as a rough estimation of the profitability of the installation if we can express the revenue and costs linearly proportional to the peak reduction and battery capacity respectively.

$$
\mathrm{R}_{\text {peak red-to-cap }}=\frac{\mathrm{P}_{\max \mathrm{i}}-\mathrm{P}_{\max \mathrm{f}}}{\mathrm{C}_{\text {bat }}}
$$

where $R_{\text {peak red-to-cap }}$ is the ratio peak reduction-to-capacity, $P_{\max i}$ is the initial peak power, $P_{\max f}$ is the final peak power after peak shaving, $\mathrm{C}_{\text {bat }}$ is the battery capacity.

SoC active time (\%): It is the average percentage of time per year that the battery is deployed for peak shaving. This metric can be very useful, especially when our intention is to combine peak shaving with other services (e.g., increasing the self-sufficiency of PV, ancillary services, Time-of-Use (ToU) prices).

$$
\begin{gathered}
\text { SoC }_{\text {act time }}=\sum_{i=1}^{1096 \cdot 96} \mathrm{i} \cdot \frac{100}{1096 \times 96} \\
\mathrm{i}=\left\{\begin{array}{c}
1,\left|\mathrm{P}_{\text {bat }}\right|>0 \\
0, \mathrm{P}_{\text {bat }}=0
\end{array}\right.
\end{gathered}
$$

where $\mathrm{SoC}_{\text {act time }}$ is the SoC active time, $\mathrm{P}_{\text {bat }}$ is the battery power, $\mathrm{i}$ is the quarter index of the simulation, $1096 \times 96$ is the total number of quarters within the 3 years period (1st January 2014-31st December 2016).

Battery utilization (cycles/year): It is the average total energy discharged by the battery within a year divided by the battery capacity. This metric can be used to assess how fast the battery reaches the end of its lifetime. Particularly for peak shaving applications, it is desirable that the battery be utilized as low as possible since our cost savings are exclusively dependent on the power component (cost in function of $\mathrm{kW}$ ). Conversely, when the aim is to increase the self-sufficiency of the installation (PV or wind), the battery utilization should be as high as possible, since our cost savings are mainly dependent on the energy component (cost in function of kWh).

$$
\mathrm{U}_{\mathrm{bat}}=\frac{\mathrm{E}_{\text {dis tot }}}{\mathrm{C}_{\mathrm{bat}} \cdot 3}
$$

where $\mathrm{U}_{\mathrm{bat}}$ is the battery utilization, $\mathrm{E}_{\mathrm{dis}}$ tot is the total discharged energy within the 3 years period, $\mathrm{C}_{\text {bat }}$ is the battery capacity.

Consumption increase (\%): It is the percentage of energy consumption increase due to efficiency losses of the battery storage system. In addition to the initial capital expenditures for the battery, the additional energy consumption should be taken into account as operating cost.

$$
A_{\text {incr }}=\frac{E_{\text {load } \mathrm{f}}-E_{\text {load } \mathrm{i}}}{E_{\text {load } \mathrm{i}}} \cdot 100
$$

where $\mathrm{A}_{\text {incr }}$ is the consumption increase, $\mathrm{E}_{\text {load } \mathrm{f}}$ and $\mathrm{E}_{\text {load } \mathrm{i}}$ is the total energy consumed within the 3-year period after and before peak shaving, respectively. 


\section{Results}

As mentioned in Section 2, the power flow model receives three variables: battery capacity, $\mathrm{C}$ rate, and time step. For each load profile in our dataset, we carried out multiple simulations by varying only the battery capacity, whereas both the time step and the $C$ rate were set at constant values. The peak threshold was calculated using the dichotomy method after defining the battery capacity.

The time step was set at $15 \mathrm{~min}$ which is the time resolution of the dataset. The $\mathrm{C}$ rate was set at $1 \mathrm{C}$; higher values are not recommended for the chosen battery technology because this would negatively impact its lifetime. Furthermore, based on our experience, for most applications, $1 \mathrm{C}$ is sufficiently high to meet a given peak threshold. In general, the extent to which we can reduce the peak power depends on the battery's energy capacity rather than its power capacity. Nevertheless, we do suggest for future research to investigate the impact of the $C$ rate as well, but in this study, it will not be addressed. Regarding the battery capacity, since we deal with several users, in order to maintain a common reference of comparison between the users, we normalized the battery capacity by dividing it by the mean power of the user. Finally, the ratio battery capacity-to-mean power was varied within $0.1-10$.

\subsection{Energetic Assessments}

The simulation results are presented in Figures 6 and 7. Knowing that our dataset consists of 40 users, it would be ineffective to illustrate 40 individual plots into the same figure. Instead, we selected five quantile elements at which the cumulative probability becomes 5\%, 25\%,50\%, 75\% and $95 \%$. This gives us a better view of the statistical distribution of each performance metric.
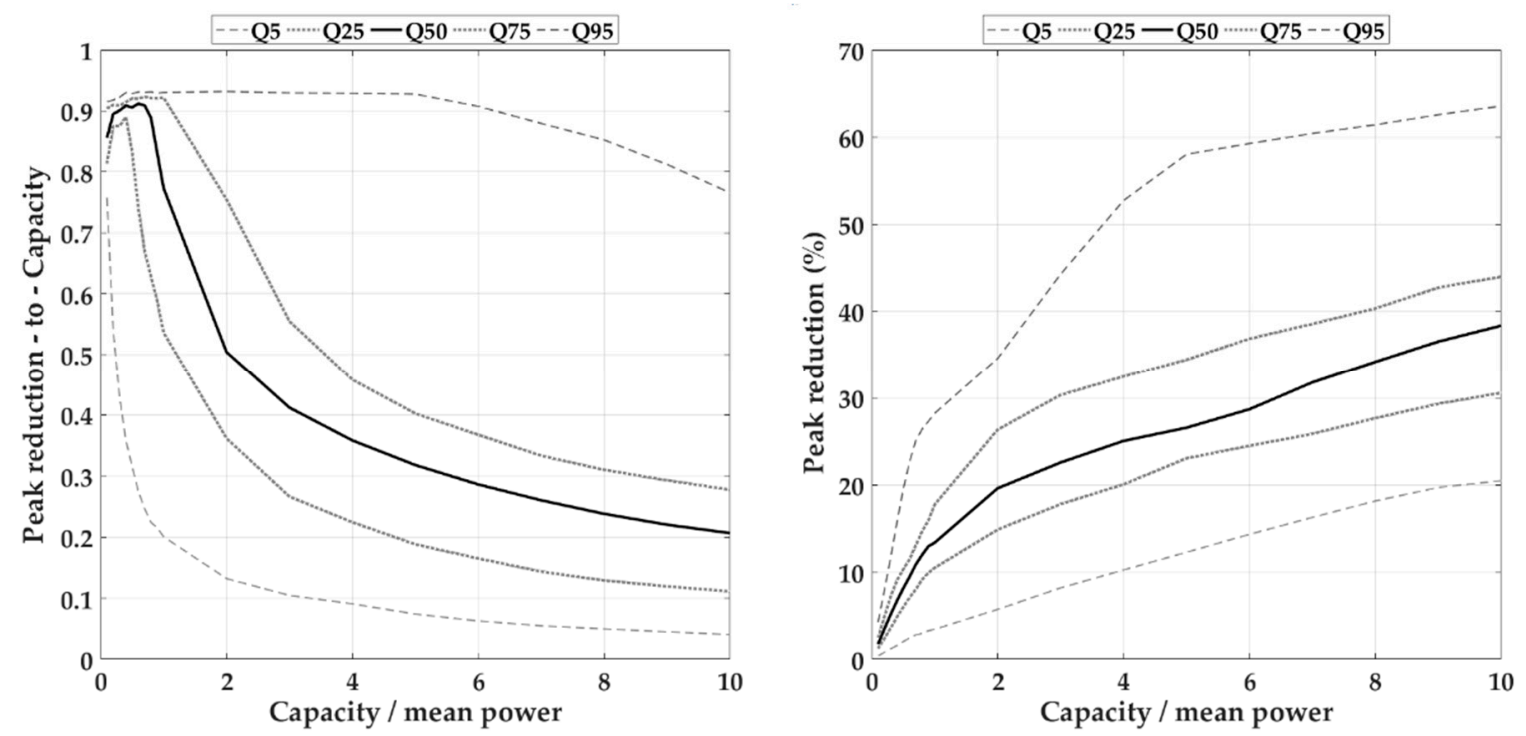

Figure 6. Simulation results: (a) Peak reduction-to-capacity (left), (b) peak reduction (right). 

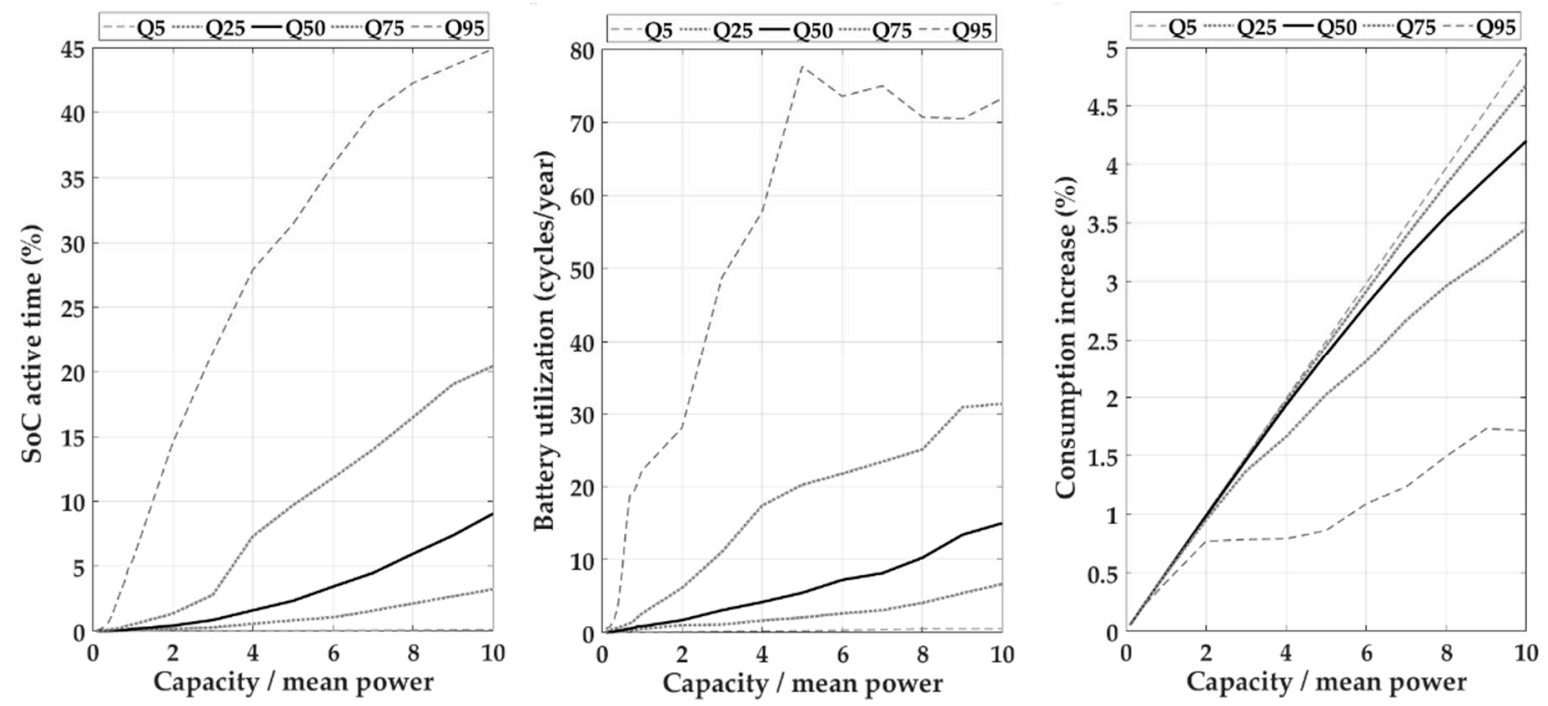

Figure 7. Simulation results: (a) SoC active time (left), (b) Battery utilization (middle), (c) Consumption increase (right).

From both Figure $6 \mathrm{a}, \mathrm{b}$, it can be concluded that the peak reduction increase decreases with the battery capacity (second derivative of the function in Figure $6 \mathrm{~b}$ is negative) or in other words: as the battery capacity increases, peak shaving becomes more difficult. For a battery capacity 2 times the mean power (e.g., a user with $30 \mathrm{~kW}$ mean power installs a $60 \mathrm{kWh}$ battery) seventy percent of the users between Q5 and Q75 achieve peak reduction in the range 0.26-1.5 times their mean power (Figure 6a). The same group of users achieves peak reduction up to $6-27 \%$ of their peak power (Figure $6 \mathrm{~b}$ ). For a battery capacity of 10 times the mean power (e.g., a user with $30 \mathrm{~kW}$ mean power installs a $300 \mathrm{kWh}$ battery) the peak reduction for that group (Q5-Q75) varies within 0.4-2.8 times their mean power (Figure $6 \mathrm{a}$ ) and $20-44 \%$ of their peak power (Figure $6 \mathrm{~b}$ ).

Regarding the SoC active time (Figure 7a), it increases with the battery capacity. The reason is that as the battery capacity increases, the peak threshold is reduced and consequently, the battery is used more frequently. An important conclusion to note is that, for most users, the SoC active time remains very low, even for large battery capacities. Seventy percent of the users between Q5 and Q75 with a battery capacity 10 times the mean power deploy their battery in the range of $0-20 \%$, or in other words the battery stays idle for at least $80 \%$ of the time during the year. This fact in itself opens up new research opportunities.

If peak shaving does occur rarely, then we could possibly hybridize our energy management system including other services as well (e.g., ancillary services, increasing the self-sufficiency of renewable energy installations). Figure $7 \mathrm{~b}$ provide another indication that the battery is underutilized, here, however in terms of lifetime expectancy. Over the entire battery capacity dimension, for ninety-five percent of the users (Q0-Q95), the battery does not deliver more than 80 cycles per year. This number is considerably lower compared to the cycle lifetime of nowadays' state-of-the-art Lithium-ion technologies (above 5000 cycles) [28]. At such low utilization rates, the battery can endure several years of use (more than a decade). Finally, it will be due to another reason why the battery was decommissioned such as a maintenance issue or simply because the battery has reached the end of its calendar lifetime. (The capacity fade effect of Lithium-ion batteries is both time-dependent (calendar lifetime) and cycle-number dependent (cycle lifetime). Regardless of its utilization, after a certain time period the battery loses a part of its initial capacity. Usually, the End of Life (EoL) of a battery is defined when its initial capacity is reduced by $20 \%$, in many critical applications (e.g., EVs) this is the time when the battery needs to be either decommissioned or repurposed for another application.)

The consumption increase is shown in Figure 7c. It is worth noting once more that the battery technology in the present study exhibits a very high energy efficiency. Undoubtedly, if other technologies 
were used (e.g., lead acid, flow batteries), the consumption increase would be higher. As can be seen from the figure, obviously, the higher the battery capacity, the higher the absolute energy losses. One reason why this happens is due to the increase of the battery utilization (see Figure $7 \mathrm{~b}$ ) and another reason is because both the battery and the dc/ac converter become bigger in size. Consider, for instance, a user with $30 \mathrm{~kW}$ mean power and a battery capacity of $300 \mathrm{kWh}$ (capacity-to-mean power is 10). Only the converter losses to (dis)charge the battery at $1 \mathrm{C}$ are approximately $15 \mathrm{~kW}$ (at $95 \%$ dc/ac efficiency). If the battery capacity was $30 \mathrm{kWh}$ (capacity-to-mean power is 1), those losses would be significantly lower $(1.5 \mathrm{~kW})$.

\subsection{Economic Evaluations}

Let us now consider a case study of how to interpret those results from an economic perspective. Table 2 lists the parameters used for our economic analysis:

- The electricity price is an average for Belgium energy invoices in the considered capacity connection range. The electricity price lies in the range of $0.2-0.25 € / \mathrm{kWh}$ [31]. Here, it must be noted that our analysis is exclusively applicable for end users with fixed electricity prices during the year; there is no Time-of-Use (ToU) dependency (e.g., day/night tariff, dynamic pricing schemes). (In case of ToU dependency, the control strategy of the battery is different. Peak demand pricing coexists with ToU pricing and therefore, we need to solve the economic optimization problem first.)

- Regarding the peak shaving compensation, for the DSO in Belgium, peak demand is defined as the highest $15 \mathrm{~min}$ load power measured by the user's AMR meter over the last 12 months. The compensation ranges approximately within $87.6-131 € / \mathrm{kW}$ per year depending on the geographical location. By dividing by the total number of hours per year $(8760 \mathrm{~h}$ ), this equals $0.01-0.015 € / \mathrm{kW} / \mathrm{h}$. (These values have been defined using a cost simulation tool from the distribution grid operator. The values apply exclusively to those users connected to the low-voltage grid with peak demand pricing.)

- With respect to the battery storage system, we consider capital expenditures at $500 € / \mathrm{kWh}$ (per $\mathrm{kWh}$ of energy capacity). The consumption increase can be approximated as linear function of the battery capacity (See Figure $7 \mathrm{c}$ ) at $0.4 \% /$ capacity-to-mean power. The battery cycle lifetime is estimated at 5000 cycles (at $80 \%$ EoL) considering normal operating conditions: (i) Ambient temperature $25^{\circ} \mathrm{C}$, (ii) SoC within 10-90\%, (iii) (dis)charge current at 1C. Given that our battery utilization is very low (80 cycles/year worst case), we will consider only calendar aging at $2 \%$ capacity loss per year. (To calculate the battery's cycle lifetime and calendar aging, under those conditions $\left(25^{\circ} \mathrm{C}, 10-90 \% \mathrm{SoC}, 1 \mathrm{C}\right)$ we received information from the manufacturer. For those interested in analytic methods to calculate the battery cycle lifetime and calendar aging, we refer to noteworthy research works [32,33].) The payback period of our investment is 10 years and we do not consider any option to resell the battery; after this period the battery is recycled.

Table 2. Peak Shaving-Parameters for Economic Feasibility.

\begin{tabular}{cc}
\hline Parameters & Values \\
\hline Payback period & 10 Years \\
Peak shaving compensation & $0.01-0.015 € / \mathrm{kW} / \mathrm{h}$ \\
Battery capex & $500 € / \mathrm{kWh}$ \\
Consumption increase rate & $0.4 \% /$ capacity-to-mean power \\
Electricity price & $0.20-0.25 € / \mathrm{kWh}$ \\
Battery capacity fade & $2 \%$ per year \\
\hline
\end{tabular}

In order for the system to be profitable, the total peak shaving compensation has to be higher than the total cost (incl. battery and losses) over the payback period; this condition is expressed in Equation (14). Next, as shown in Equation (15), the peak reduction-to-capacity ratio can be expressed in function 
of all economic parameters. Finally, by replacing with the values of Table 2, it can be concluded that the ratio needs to be higher than $0.43-0.67$ (Equation (16)).

$$
\begin{gathered}
\text { Rev } \cdot 8760 \cdot \text { ROI } \cdot \Delta \mathrm{P}_{\text {peak }}>\text { Cap } \cdot\left(\text { Cost }_{\text {bat }}+\text { Rate }_{\text {cons incr }} \cdot \mathrm{P}_{\text {elect }} \cdot 8760 \cdot \text { ROI }\right) \\
\frac{\Delta \mathrm{P}_{\text {peak }}}{\text { Cap }}>\frac{\text { Cost }_{\text {bat }}+\text { Rate }_{\text {cons incr }} \cdot \mathrm{P}_{\text {elect }} \cdot 8760 \cdot \text { ROI }}{\operatorname{Rev} \cdot 8760 \cdot \text { ROI }} \\
\frac{\Delta \mathrm{P}_{\text {peak }}}{\text { Cap }}>0.43-0.67
\end{gathered}
$$

where $\Delta \mathrm{P}_{\text {peak }}$ is the peak reduction, $\mathrm{ROI}$ is the return of investment (payback period), Rev is the peak compensation (revenue), Cap is the battery capacity, Cost $_{\text {bat }}$ is the battery capex, Rate cons incr $_{\text {is the }}$ rate of consumption increase and $\mathrm{P}_{\text {elect }}$ is the electricity price.

Over the 10-year period, the total capacity loss of the battery will be $20 \%$. Consequently, to ensure that the peak threshold will always be met, we have to oversize the battery capacity. Finally, the results of the economic feasibility study are illustrated in Figure 8 . Figure 8 can be made easily from Figure $6 a$ (see Section 3.1 ) by adding a $20 \%$ margin to the minimum battery capacity requirement. The color at each point $[x, y]$ represents the total number of users whose peak reduction-to-capacity exceeds the $y$ value (similarly to the quantile plots of Figure 6a). The yellow and green dashed lines represent the profitability thresholds 0.43 and 0.67 , respectively (see Equation (16)). As can be seen, there are several positive use cases; of course the number of positive cases depends on the battery size. To give an example, when the ratio capacity/mean power equals 2 , there are 15-20 users exceeding the value 0.43 (lower profitability threshold), whereas when the ratio capacity/mean power becomes 10 , there are only $0-5$ users exceeding that value (0.43). With that being said, we do now have an estimation of the profitability margins for the Belgian use cases.

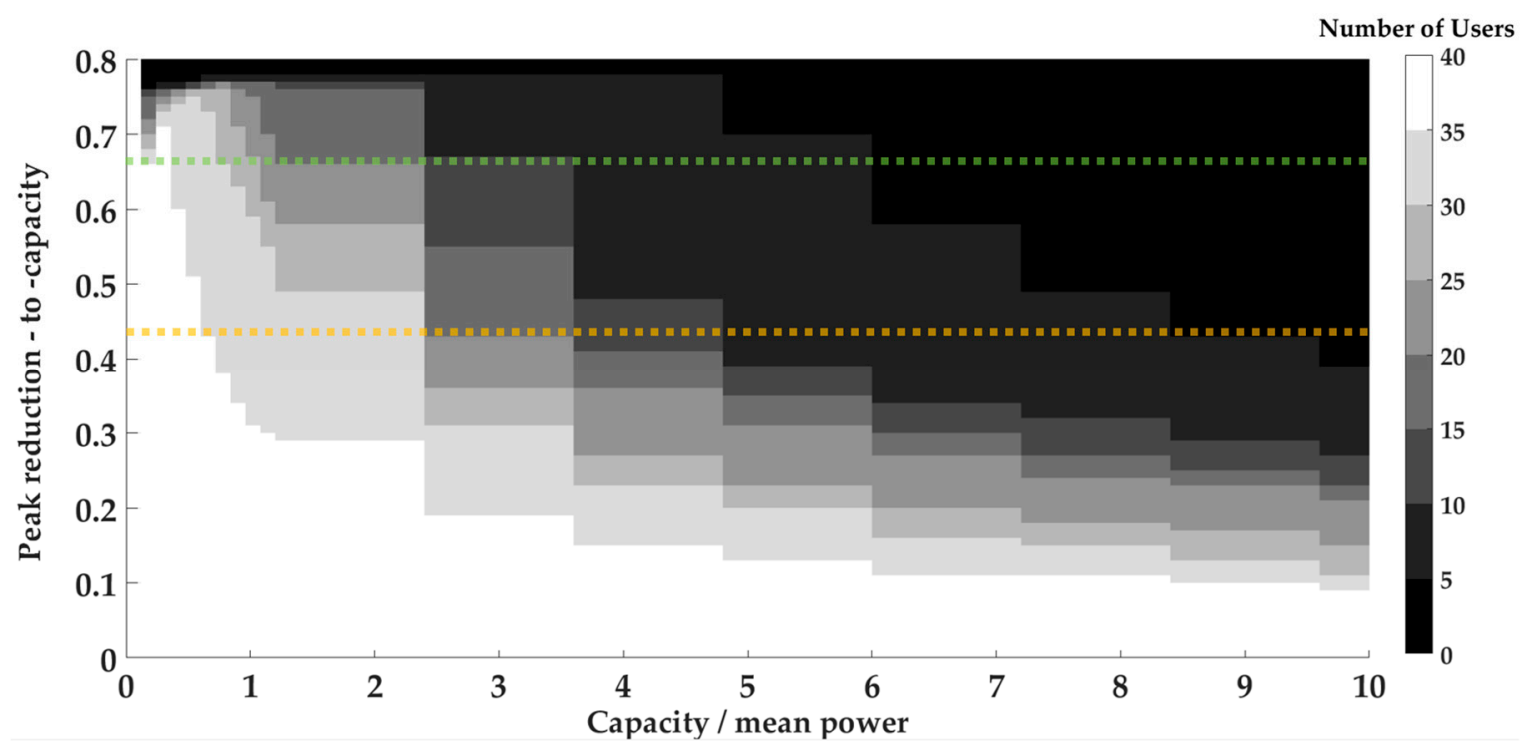

Figure 8. Peak shaving-results of economic feasibility study. At each point $[x, y]$, the color represents the total number of users whose peak reduction-to-capacity exceeds the y value. The yellow and green dashed lines represent the profitability thresholds 0.43 and 0.67 , respectively (see Equation (16)).

Needless to say that our estimation is strongly influenced by the considered parameter values (Table 2). Even without changing neither the electricity price nor the peak shaving compensation, simply by varying the payback period and/or the battery capex we would get different results. Here, it is worth noting that the battery capex at $500 € / \mathrm{kWh}$ is very realistic for the time being and it is expected to decline further in the coming years [34]. (To define the battery capex we consulted manufacturers 
and received offers.) As a general conclusion, we can note that given the current electricity prices (fixed, no ToU dependency) and capital expenditures, particularly for Belgium, peak shaving through battery storage seems to be interesting from an economic perspective for several low-voltage enterprises.

\section{Discussion and Conclusions}

To summarize briefly what has been done, a model was developed in Matlab/Simulink for peak shaving. The dichotomy method was proposed as an optimization algorithm to find the minimum threshold above which we are $100 \%$ certain that the peak will never be exceeded. The model was tested for 40 low-voltage users with peak demand charge derived from the Belgian grid operator. We introduced five performance metrics to evaluate the simulation results. Furthermore, we gave an example how to interpret the results from economic perspective and explored the profitability of the application in Belgium. Below is a summary of the most important conclusions resulting from our analysis:

- For a battery capacity 2 times the mean power, the peak reduction of the group of users Q5-Q75 varies between $6 \%$ and $27 \%$, whereas for a battery capacity 10 times the mean power, the peak reduction ranges between $20 \%$ and $44 \%$.

- The SoC active time is limited for almost all cases. Even with an over-dimensioned battery (capacity-to-mean power is 10), for seventy-five percent of the users (Q0-Q75), the battery remains idle for at least $80 \%$ for the time. Consequently, peak shaving could possibly be hybridized with other services (e.g., increasing PV self-sufficiency, ancillary services) in order to accelerate the return of investment of the battery storage system. (By adding more revenue streams (stacked services) the payback period of the investment can be reduced.)

- The battery utilization is very low, up to 80 cycles per year in worst case. This number is significantly lower compared to the cycle lifetime of nowadays' lithium-ion batteries.

- The consumption increase gets higher with the battery capacity. It lies in the range $0 \%$ to $5 \%$ and does not substantially impact the operating cost of the system.

- From an economic perspective, peak shaving seems to be interesting for several low-voltage users in Belgium under the current capex and fixed electricity prices (no ToU dependency).

One of our main conclusions is that the battery utilization (SoC active time and number of cycles) is very low for almost all users. Consequently, there seems to be enough potential to let our battery provide additional services during those inactive periods in order to accelerate the payback period of our investment. Which services can be combined and how efficiently this can be done is certainly a topic to be addressed by future research works.

As an initial step, we suggest studying the predictability of the load profile. In our study, we consider the battery to be available for peak shaving $100 \%$ of the time; therefore, there is no need to know in advance when the peak occurs. However, in hybrid applications, time must be allocated appropriately and as a result load prediction plays an important role. To better explain this argument, let us consider two different load profiles derived from our dataset, user A and B (Figures 9 and 10 respectively). Although the battery utilization is in both cases very low (peak occurs rarely), user A is by far more predictable than the user B. For user A, the peak occurrence is dependent on the day, the time of use and the temperature, whereas for user B, there seem to be no clear explanatory variables. Consequently, user B cannot know how to allocate his inactive time to other services; hence, the battery remains underutilized solely reserved for peak shaving. Closing this paragraph, we note that, so far, most research works on battery storage have addressed only single applications. In our view, the concept of hybridization will gain more attention in the coming years as users gradually acquire more incentives to interact with the grid. 


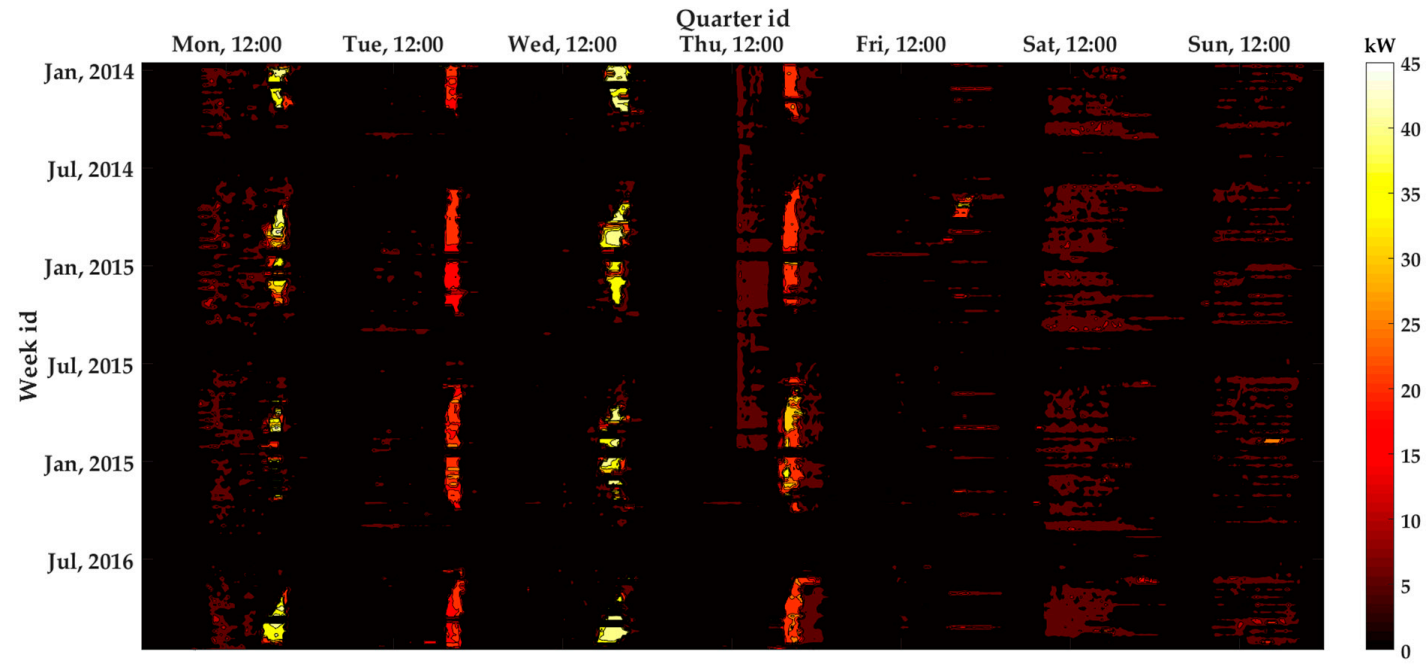

Figure 9. Thermal image-predictable load profile.

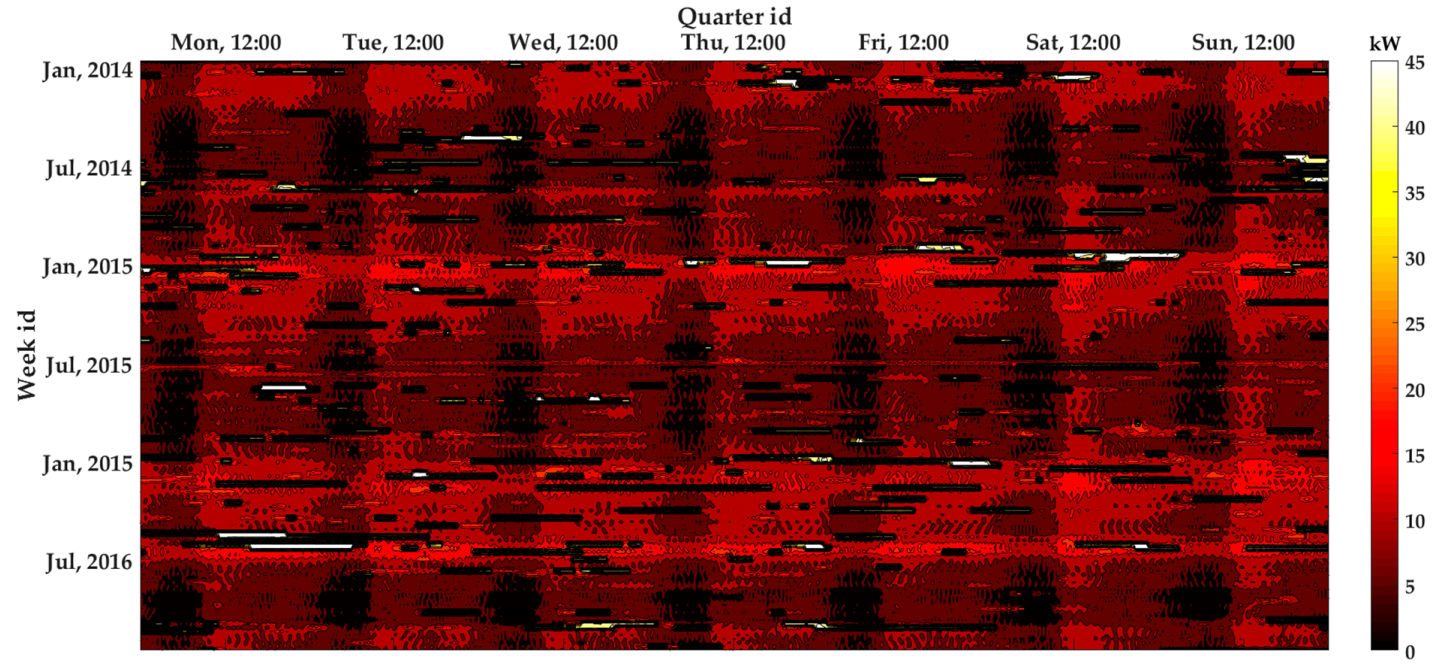

Figure 10. Thermal image-unpredictable load profile.

Supplementary Materials: The following are available online at http://www.mdpi.com/1996-1073/13/5/1183/s1, Dataset S1: "40 LV consumers with peak demand pricing in Belgium, From 1-1-2014 to 31-12-2016.zip".

Author Contributions: Conceptualization, V.P. and J.D.; methodology, V.P. and J.D.; software, V.P.; validation, V.P.; formal analysis, V.P.; investigation, V.P. and J.D.; resources, J.D.; data curation, C.D.; writing-original draft preparation, V.P.; writing - review and editing, J.D., J.K. and C.D.; visualization, V.P.; supervision, J.D., J.K. and C.D.; project administration, V.P. and J.D.; funding acquisition, J.D. All authors have read and agreed to the published version of the manuscript.

Funding: The research received no external funding.

Acknowledgments: We would like to thank the Flemish distribution system operator for providing the dataset for experimentation. Normally, such large datasets are very difficult to find within the research community.

Conflicts of Interest: The authors declare no conflict of interest.

\section{References}

1. Arantegui, R.L.; Jager-Waldau, A. Photovoltaics and wind status in the European Union after the Paris Agreement. Renew. Sustain. Energy Rev. 2018, 81, 2460-2471. [CrossRef]

2. Petinrin, J.O.; Shaaban, M. Impact of renewable generation on voltage control in distribution systems. Renew. Sustain. Energy Rev. 2016, 65, 770-783. [CrossRef] 
3. Antonelli, M.; Desideri, U.; Franco, A. Effects of large scale penetration of renewables: The Italian case in the years 2008-2015. Renew. Sustain. Energy Rev. 2018, 81, 3090-3100. [CrossRef]

4. Simshauser, P. Distribution network prices and solar PV: Resolving rate instability and wealth transfers through demand tariffs. Energy Econ. 2016, 54, 108-122. [CrossRef]

5. Lummi, K.; Rautiainen, A.; Jarventausta, P.; Heine, P.; Lehtinen, J.; Hyvarinen, M. Cost-causation based approach in forming power-based distribution network tariff for small customers. In Proceedings of the 2016 13th International Conference on the European Energy Market (EEM), Porto, Portugal, 6-9 June 2016; pp. 1-5.

6. Strielkowski, W.; Streimikiene, D.; Bilan, Y. Network charging and residential tariffs: A case of household photovoltaics in the United Kingdom. Renew. Sustain. Energy Rev. 2017, 77, 461-473. [CrossRef]

7. VREG. Consultatiedocument Tariefstructuur Periodieke Distributienettarieven Elektriciteit Voor Klanten Met een Kleinverbruiksmeetinrichting; VREG: Flanders, Belgium, 2019.

8. VREG. Consultatiedocument Tariefstructuur Periodieke Distributienettarieven Elektriciteit Voor Klanten Met een Grootverbruiksmeetinrichting; VREG: Flanders, Belgium, 2019.

9. Nyholm, E.; Goop, J.; Odenberger, M.; Johnsson, F. Solar photovoltaic-battery systems in Swedish households-Self-consumption and self-sufficiency. Appl. Energy 2016, 183, 148-159. [CrossRef]

10. Silva, G.E.; Hendrick, P. Lead-acid batteries coupled with photovoltaics for increased electricity self-sufficiency in households. Appl. Energy 2016, 178, 856-867. [CrossRef]

11. Bertsch, V.; Geldermann, J.; Luhn, T. What drives the profitability of household PV investments, self-consumption and self-sufficiency? Appl. Energy 2017, 204, 1-15. [CrossRef]

12. Huvilinna, J. Value of Battery Energy Storage at Ancillary Service Markets; Aalto University: Espoo, Finland, 2015.

13. Koller, M.; Borsche, T.; Ulbig, A.; Andersson, G. Review of grid applications with the Zurich 1 MW battery energy storage system. Electr. Power Syst. Res. 2015, 120, 128-135. [CrossRef]

14. Staffell, I.; Rustomji, M. Maximising the value of electricity storage. J. Energy Storage 2016, 8, $212-225$. [CrossRef]

15. Oudalov, A.; Cherkaoui, R.; Beguin, A. Sizing and optimal operation of battery energy storage system for peak shaving application. In Proceedings of the 2007 IEEE Lausanne Power Tech, Lausanne, Switzerland, 1-5 July 2007. [CrossRef]

16. Leadbetter, J.; Swan, L. Battery storage system for residential electricity peak demand shaving. Energy Build. 2012, 55, 685-692. [CrossRef]

17. Rowe, M.; Yunusov, T.; Haben, S.; Singleton, C.; Holderbaum, W.; Potter, B. A Peak Reduction Scheduling Algorithm for Storage Devices on the Low Voltage Network. In IEEE Transactions on Smart Grid; IEEE: Piscataway, NJ, USA, 2014; Volume 5, pp. 2115-2124. [CrossRef]

18. Govindan, S.; Wang, D.; Sivasubramaniam, A.; Urgaonkar, B. Leveraging Stored Energy for Handling Power Emergencies in Aggressively Provisioned Datacenters; ACM Sigplan Notices: New York, NY, USA, 2012; pp. $75-86$.

19. Kontorinis, V.; Zhang, L.E.; Aksanli, B.; Sampson, J.; Homayoun, H.; Pettis, E.; Tullsen, D.M.; Rosing, T.S. Managing Distributed UPS Energy for Effective Power Capping in Data Centers. In Proceedings of the 2012 39th Annual International Symposium on Computer Architecture (ISCA), Portland, OR, USA, 9-13 June 2012; pp. 488-499.

20. Fitzgerald, G.; Mandel, J.; Morris, J.; Touati, H. The Economics of Battery Energy Storage: How Mutli-Use, Customer-Sited Batteries Deliver the Most Services and Value to Customers and the Grid; Rocky Mountain Institute: New York, NY, USA, 2015.

21. Smartest Energy. Making the Commercial Case for Battery Storage; Smartest Energy: London, UK, 2016.

22. Lucas, A.; Chondrogiannis, S. Smart grid energy storage controller for frequency regulation and peak shaving, using a vanadium redox flow battery. Int. J. Electr. Power 2016, 80, 26-36. [CrossRef]

23. Chua, K.H.; Lim, Y.S.; Morris, S. A novel fuzzy control algorithm for reducing the peak demands using energy storage system. Energy 2017, 122, 265-273. [CrossRef]

24. Aksanli, B.; Rosing, T.; Pettis, E. Distributed Battery Control for Peak Power Shaving in Datacenters. In Proceedings of the 2013 International Green Computing Conference Proceedings, Arlington, VA, USA, 27-29 June 2013.

25. Palasamudram, D.S.; Sitaraman, R.K.; Urgaonkar, B.; Urgaonkar, R. Using batteries to reduce the power costs of internet-scale distributed networks. In Proceedings of the Third ACM Symposium on Cloud Computing, San Jose, CA, USA, 14-17 October 2012; pp. 1-14. 
26. Chua, K.H.; Lim, Y.S.; Morris, S. Energy storage system for peak shaving. Int. J. Energy Sect. Manag. 2016, 10, 3-18. [CrossRef]

27. Garcia-Plaza, M.; Carrasco, J.E.G.; Alonso-Martinez, J.; Asensio, A.P. Peak shaving algorithm with dynamic minimum voltage tracking for battery storage systems in microgrid applications. J. Energy Storage 2018, 20, 41-48. [CrossRef]

28. Guney, M.S.; Tepe, Y. Classification and assessment of energy storage systems. Renew. Sustain. Energy Rev. 2017, 75, 1187-1197. [CrossRef]

29. Ansean, D.; Gonzalez, M.; Viera, J.C.; Garcia, V.M.; Blanco, C.; Valledor, M. Fast charging technique for high power lithium iron phosphate batteries: A cycle life analysis. J. Power Sources 2013, 239, 9-15. [CrossRef]

30. Papadopoulos, V.; Knockaert, J.; Develder, C.; Desmet, J. Investigating the need for real time measurements in industrial wind power systems combined with battery storage. Appl. Energy 2019, 247, 559-571. [CrossRef]

31. VREG. Evolutie Energieprijzen en Distributienettarieven. Available online: https://www.vreg.be/nl/evolutieenergieprijzen-en-distributienettarieven (accessed on 10 October 2019).

32. Liu, K.L.; Hu, X.S.; Yang, Z.L.; Xie, Y.; Feng, S.Z. Lithium-ion battery charging management considering economic costs of electrical energy loss and battery degradation. Energy Convers. Manag. 2019, 195, 167-179. [CrossRef]

33. Liu, K.; Li, Y.; Hu, X.; Lucu, M.; Widanalage, D. Gaussian Process Regression with Automatic Relevance Determination Kernel for Calendar Aging Prediction of Lithium-ion Batteries. IEEE Trans. Ind. Inform. 2019. [CrossRef]

34. Berckmans, G.; Messagie, M.; Smekens, J.; Omar, N.; Vanhaverbeke, L.; Van Mierlo, J. Cost Projection of State of the Art Lithium-Ion Batteries for Electric Vehicles Up to 2030. Energies 2017, 10, 1314. [CrossRef]

(C) 2020 by the authors. Licensee MDPI, Basel, Switzerland. This article is an open access article distributed under the terms and conditions of the Creative Commons Attribution (CC BY) license (http://creativecommons.org/licenses/by/4.0/). 